\title{
Detection and phylogenetic characterization of Theileria spp. and Anaplasma marginale in Rhipicephalus bursa in Portugal
}

\author{
Joana Ferrolho a , Sandra Antunes ${ }^{a}$, Ana S. Santos ${ }^{b}$, Rita Velez ${ }^{b}$, Ludovina Padre ${ }^{c}$, \\ Alejandro Cabezas-Cruz ${ }^{\mathrm{d}}$, Maria Margarida Santos-Silva ${ }^{\mathrm{b}}$, Ana Domingos ${ }^{\mathrm{a}, *}$ \\ a Instituto de Higiene e Medicina Tropical - Global Health and Tropical Medicine, Rua da Junqueira 100, 1349-008 Lisboa, Portugal \\ b Centro de Estudos de Vetores e Doenças Infeciosas Dr. Francisco Cambournac, Instituto Nacional de Saúde Dr. Ricardo Jorge I.P., Águas de Moura, Portugal \\ ${ }^{\mathrm{c}}$ Universidade de Évora, Évora, Portugal \\ d Center for Infection and Immunity of Lille (CIIL), INSERM U1019 - CNRS UMR 8204, Université de Lille, Institut Pasteur de Lille, 1 rue Professeur Calmette, \\ 59019 Lille Cedex, France
}

\section{A R T I C L E I N F O}

\section{Article history:}

Received 25 August 2015

Received in revised form 9 December 2015

Accepted 10 January 2016

Available online xxx

\section{Keywords:}

Rhipicephalus bursa

Tick-borne pathogens

Theileria annulata

Theileria equi

Anaplasma marginale

Portugal

\begin{abstract}
A B S T R A C T
Ticks are obligatory blood-sucking arthropod (Acari:Ixodida) ectoparasites of domestic and wild animals as well as humans. The incidence of tick-borne diseases is rising worldwide, challenging our approach toward diagnosis, treatment and control options. Rhipicephalus bursa Canestrini and Fanzago, 1877, a two-host tick widely distributed in the Palearctic Mediterranean region, is considered a multi-host tick that can be commonly found on sheep, goats and cattle, and occasionally on horses, dogs, deer and humans. $R$. bursa is a species involved in the transmission of several tick-borne pathogens with a known impact on animal health and production. The aim of this study was to estimate $R$. bursa prevalence in Portugal Mainland and circulating pathogens in order to contribute to a better knowledge of the impact of this tick species. Anaplasma marginale and Theileria spp. were detected and classified using phylogenetic analysis. This is the first report of Theileria annulata and Theileria equi detection in $R$. bursa ticks feeding on cattle and horses, respectively, in Portugal. This study contributes toward the identification of currently circulating pathogens in this tick species as a prerequisite for developing future effective anti-tick control measures.
\end{abstract}

@ 2016 Published by Elsevier GmbH.

\section{Introduction}

During the last two decades, a growing interest in tick-borne diseases from veterinary, medical, and public health perspectives has emerged (Jongejan and Uilenberg, 2004). The worldwide prevalence of these diseases is steadily rising, challenging how we approach diagnosis, treatment and preventative control measures, and underlining the importance of the One Health concept (DantasTorres et al., 2012). Ticks are known to have a significant impact on host species through their feeding behavior, causing direct skin and sub-cutaneous tissue damage and blood depletion, whilst acting as vectors of different pathogens, such as viruses, bacteria,

\footnotetext{
* Corresponding author.

E-mail addresses: joana.ferrolho@ihmt.unl.pt

(J. Ferrolho), santunes@ihmt.unl.pt (S. Antunes), a_s_p_s@vodafone.pt (A.S. Santos), rita_vlz@yahoo.co.uk (R. Velez), lpadre@ue.pt (L. Padre),

cabezasalejandrocruz@gmail.com (A. Cabezas-Cruz),

m.santos.silva@insa.min-saude.pt (M.M. Santos-Silva), adomingos@ihmt.unl.pt (A. Domingos).
}

protozoa or fungi (Bell-Sakyi et al., 2007; Colebrook and Wall, 2004). It is estimated that approximately $10 \%$ of tick species exert an active role as biological vectors in the transmission of tick-borne pathogens, including several zoonotic agents (Heyman et al., 2010; Jongejan and Uilenberg, 2004; Labuda and Nuttall, 2004). Amongst these tick species is Rhipicephalus bursa Canestrini and Fanzago, 1877, classified in the Ixodidae family (Walker et al., 2000). Epidemiological studies have identified $R$. bursa as being widely distributed in the Mediterranean region where the climate is typically characterized by long dry summers and cold winters (Walker et al., 2000; Yeruham et al., 1985). Considered a multi-host tick, the primary hosts of this species include cattle, sheep, and goats (Santos-Silva et al., 2011; Walker et al., 2000). Though less common, this tick can also be found in other domestic animals, as well as in wild ungulates and small-medium sized mammals and sporadically, in humans (de la Fuente et al., 2004b; Mihalca et al., 2012; Psaroulaki et al., 2006; Santos-Silva et al., 2011; Satta et al., 2011; Walker et al., 2000). R. bursa has been described as being involved in the transmission of agents of the genus Anaplasma (de la Fuente et al., 2004a), Babesia (Altay et al., 2008; M’Ghirbi et al., 2010), 
Theileria (Garcia-Sanmartin et al., 2008), Rickettsia (Boudebouch et al., 2009; de Sousa et al., 2006; Ioannou et al., 2011; Toledo et al., 2009) among others, with a known impact on animal health. The main objective of this study was to provide up-dated information regarding the currently circulating pathogens in $R$. bursa and their phylogenetic characterization, in Portugal Mainland, for the future development and planning of effective tick control measures.

\section{Materials and methods}

\subsection{Ticks samples}

A total of 266 R. bursa ticks were included in this study. Ticks were collected from 2007 to 2014 in 24 local administrative units municipalities (LAU I) belonging to 11 out of the 28 Mainland Portuguese subregions (Nomenclature of Territorial Units for Statistics regions - NUTS III), including the intermunicipal community (IMC) of Minho-Lima, IMC Cávado, IMC Ave, Alto Trás-os-Montes, IMC Douro, Beira Interior Sul, IMC Médio Tejo, Alto Alentejo, Peninsula de Setúbal, IMC Alentejo Litoral and IMC Baixo Alentejo. Fig. 1 shows the number of $R$. bursa specimens collected and the locations, according to geographical coordinates and subregions (QGIS 2.4.0. Chugiak). Ticks were either removed from domestic animals by local veterinarians or collected by flagging/dragging the vegetation and further identified to species level using morphological keys, as previously described (Santos-Silva et al., 2011). After identification, ticks were preserved in $70 \%$ alcohol, separated according to instars, origin and site of collection, until further manipulation.

\subsection{DNA extraction, $P C R$ screening and amplicon sequencing}

Each tick was recovered from ethanol, rinsed in $\mathrm{pH} 7.4$ phosphate-buffered saline (PBS), homogenized and used for DNA extraction using TriReagent (Sigma-Aldrich, Lisbon, Portugal), as previously described (Antunes et al., 2015). DNA concentration and purity was accessed by spectrophotometry (Thermo Scientific NanoDrop 2000, Lisbon, Portugal). DNA was stored at $-20^{\circ} \mathrm{C}$ for downstream application.

An initial screening to validate DNA extraction was performed in a group of samples randomly selected, representing $20 \%$ of all extracted ticks. Using the primer pair T1B/T2A that targets a $360 \mathrm{bp}$ fragment of tick mitochondrial $12 S$ rDNA, a PCR was performed as previously described (Beati and Keirans, 2001).

To amplify Anaplasma spp. and Ehrlichia spp. a broad range PCR screen with the primers EHR16sD/EHR16sR was conducted as reported before (Inokuma et al., 2000). This primer set amplifies a $345 \mathrm{bp}$ fragment of the $16 \mathrm{~S}$ rRNA gene of bacteria within the family Anaplasmataceae, including the genera Anaplasma, Ehrlichia, Neorickettsia, and Wolbachia. For piroplasms, a PCR targeting a $408 \mathrm{bp}$ fragment from the small subunit of $18 \mathrm{~S}$ rDNA of Babesia spp. and Theileria spp. was conducted using the primer set Piro-A and Piro-B as described elsewhere (Harrus et al., 2011). To detect Coxiella burnetii DNA, a nested-touchdown PCR was done using the primer pairs Trans $1 / 2$ followed by Trans3/4 that amplify a 243 bp fragment of the repetitive insertion element IS1111 (Lorenz et al., 1998). Primers were obtained from StabVida (Lisbon, Portugal). PCR were performed in $25 \mu \mathrm{l}$ reactions with Supreme NZYTaq $2 \times$ Green Master Mix (NZYTech, Lisbon, Portugal), $1 \mu \mathrm{M}$ primers and up to $5 \mu \mathrm{l}$ of template DNA. Nuclease-free water was used as negative control. As positive controls, DNA extracted from reference strains was used: Anaplasma marginale Va-48 strain, Babesia bigemina Israel strain, C. burnetii Nine Mile strain (Vircell, Spain) and Theileria annulata (Uzbek strain). Amplifications were performed in a T100 thermal cycler (Biorad, Amadora, Portugal) according to references

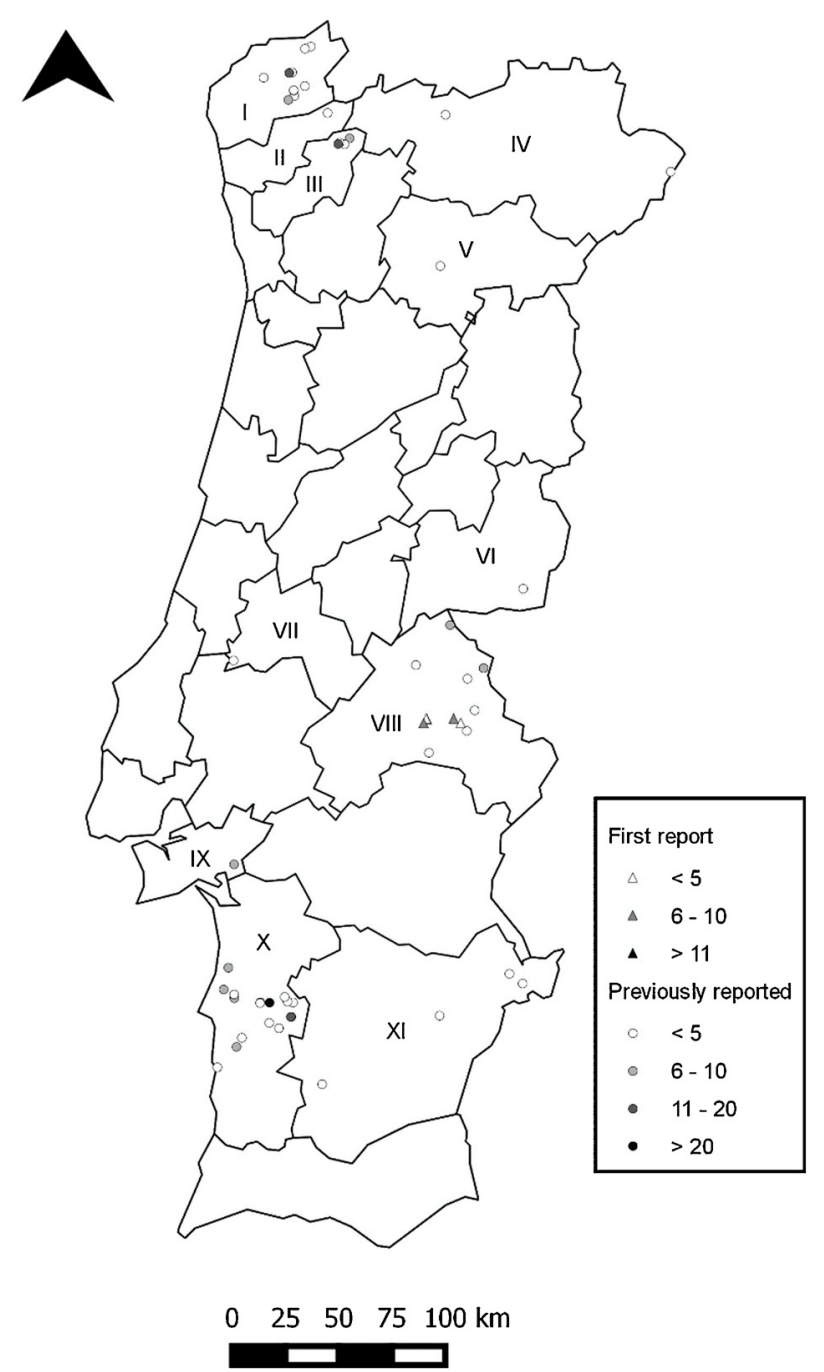

Fig. 1. Geographical locations and number of Rhipicephalus bursa found according to NUTS III Subregions. Map was performed using the QGIS 2.4.0. Chugiak program. Circles - Corresponds to the exact coordinates of collection sites in previously reported municipalities; Triangles - Corresponds to the exact coordinates of collection sites in new municipalities; I - Intermunicipal community (IMC) of Minho-Lima, II - IMC Cávado, III - IMC Ave, IV - Alto Trás-os-Montes, V - IMC Douro, VI - Beira Interior Sul, VII - IMC Médio Tejo, VIII - Alto Alentejo, IX - Peninsula de Setúbal, X - IMC Alentejo Litoral, XI - IMC Baixo Alentejo.

(Harrus et al., 2011; Inokuma et al., 2000; Lorenz et al., 1998). Positive amplicons were purified using the NZYGelpure kit (NZYtech, Lisbon, Portugal) and sent for Sanger sequencing at StabVida (Lisbon, Portugal). The obtained sequences were aligned, compared to those already deposited in the NCBI nucleotide database (http:// blast.ncbi.nlm.nih.gov/Blast).

\subsection{Phylogenetic analysis}

The phylogenetic analyses were conducted with A. marginale, Anaplasma phagocytophilum, Anaplasma platys, Ehrlichia canis, Ehrlichia chaffeensis, Ehrlichia ewingii, Ehrlichia canis 16S rDNA (family Anaplasmataceae) and Theileria spp. $18 \mathrm{~S}$ rDNA (Apicomplexan) nucleotide sequences aligned with MAFFT (v7) configured for the highest accuracy (Katoh and Standley, 2013). After alignment, the sequences were cured using Gblocks (Castresana, 2000) with the following parameters: minimum length of a block after gap cleaning: 10 , no gap positions were allowed in the final alignment and all segments with contiguous nonconserved positions bigger than 
Table 1

Results of PCR screening for tick-borne pathogens in Rhipicephalus bursa from Mainland Portugal.

\begin{tabular}{|c|c|c|c|c|c|c|c|c|c|c|}
\hline \multirow{2}{*}{$\begin{array}{l}\text { Sub regions/no } \\
\text { municipalities }^{\mathrm{a}}\end{array}$} & & \multicolumn{8}{|c|}{ No of positives/tested ticks ${ }^{b}$} & \multirow{2}{*}{$\begin{array}{l}\text { Sequencing } \\
\text { results }\end{array}$} \\
\hline & & Overall & B. taurus & C. familiaris & C. hircus & E. caballus & O. aries & S. scrofa & Vegetation & \\
\hline IMC Minho-Lima & 4 & 33 & - & - & - & - & - & - & $15 \mathrm{~m} ; 18 \mathrm{f}$ & \\
\hline IMC Cávado & 1 & 3 & $3 \mathrm{~m}$ & - & - & - & - & - & - & \\
\hline IMC Ave & 1 & $2 / 23$ & - & - & - & $2 / 9 \mathrm{~m} ; 14 \mathrm{f}$ & - & - & - & 2 T. equi \\
\hline Alto Trás-os-Montes & 2 & 6 & $3 \mathrm{~m} ; 2 \mathrm{f}$ & $1 \mathrm{~m}$ & - & - & - & - & - & \\
\hline IMC Douro & 1 & 3 & - & $3 f$ & - & - & - & - & - & \\
\hline Beira Interior Sul & 1 & $\mathbf{1} / 4$ & - & - & - & - & $\mathbf{1} / 4 \mathrm{f}$ & - & - & 1 A. marginale \\
\hline IMC Médio Tejo & 1 & 1 & - & - & - & - & - & - & $1 \mathrm{~m}$ & \\
\hline Peninsula de Setúbal & 1 & $2 / 6$ & - & - & - & - & - & - & $3 \mathrm{~m} ; 2 / 3 \mathrm{f}$ & 1 A. marginale \\
\hline Alto Alentejo & 7 & $\mathbf{1} / 61$ & 1f; 43n; 31 & - & $3 \mathrm{~m} ; \mathbf{1} / 7 \mathrm{f}$ & $1 \mathrm{~m} ; 1 \mathrm{f} ; 1 \mathrm{n}$ & - & $1 \mathrm{n}$ & - & 1 A. marginale \\
\hline IMC Alentejo Litoral & 2 & $4 / 120$ & $\mathbf{2} / 65 \mathrm{~m} ; \mathbf{2} / 49 \mathrm{f}$ & $2 \mathrm{~m} ; 3 \mathrm{f}$ & - & - & $1 \mathrm{~m}$ & - & - & $\begin{array}{l}3^{c} \text { A. marginale; } \\
1 \text { T. annulata }\end{array}$ \\
\hline IMC Baixo Alentejo & 3 & 6 & $3 f$ & - & - & - & $3 \mathrm{f}$ & - & - & \\
\hline Total & 24 & $10 / 266$ & $\begin{array}{l}2 / 71 \mathrm{~m} ; 2 / 55 \mathrm{f} \\
43 \mathrm{n} ; 31\end{array}$ & $3 \mathrm{~m} ; 6 \mathrm{f}$ & $3 \mathrm{~m} ; \mathbf{1} / 7 \mathrm{f}$ & $\begin{array}{l}10 \text { males, } \\
15 \text { females, } \\
1 \text { nymph }\end{array}$ & $1 \mathrm{~m} ; \mathbf{1} / 7 \mathrm{f}$ & $1 \mathrm{n}$ & $19 \mathrm{~m} ; \mathbf{2} / 21 \mathrm{f}$ & \\
\hline
\end{tabular}

\footnotetext{
a Portuguese Mainland according to Nomenclature of Territorial Units for Statistics regions - NUTS III and local administrative units or municipalities (LAU I)

b According to tick instars: m-male; f-female; n-nymph; l-larva.

c One male and two females with Anaplasma marginale.
}

4 were rejected. Two phylogenetic trees were built, one for members of Anaplasmataceae and the other for Apicomplexan parasites. Phylogenetic trees were reconstructed using neighbor joining (NJ) based on Kimura 2-parameters genetic distances. Phylogenetic inference and model selection were performed using MEGA 6 (Tamura et al., 2013). The reliability for the internal branches of $\mathrm{NJ}$ was assessed using the bootstrapping method (1000 bootstrap replicates). Graphical representation and editing of the phylogenetic trees were performed with EvolView (Zhang et al., 2012). The accession numbers and geographic origins of the isolates used in the phylogenetic analysis are shown in the phylogenetic trees. The sequences obtained in this study were submitted to GenBank and identified with the respective accession number.

\section{Results}

From the $266 R$. bursa studied, 226 were found feeding on animals ( 88 males, 90 females, 45 nymphs and 3 larvae) and 40 were questing ticks ( 19 males and 21 females). As previously mentioned, ticks were obtained from 24 municipalities that correspond to 11 Portuguese Mainland subregions (NUTS III). Fig. 1 shows the number and geographical location of $R$. bursa according to those subregions. Most of the ticks were obtained from Alentejo Litoral (45.1\%), followed by Alto Alentejo (22.9\%), Minho-Lima (12.4\%) and Ave (8.6\%). A smaller number of ticks were found in the remaining subregions, ranging from 2.3 to $0.4 \%$ (Table 1 ). Of note is the fact that two of the seven municipalities from Alto Alentejo represent new data records for current $R$. bursa distribution (Alter do Chão and (rato) as the occurrence of this tick species was not previously reported in those places (Fig. 1). Regarding seasonality, adults were mostly found during spring and summer months, contrasting with immatures that were obtained from fall to winter. Considering tickhost associations, $R$. bursa were removed from cattle (Bos taurus; $N=172$ ), followed by horses (Equus caballus; $N=26$ ), goats (Capra hircus; $N=10$ ), sheep (Ovis aries; $N=8$ ), dogs (Canis familiaris; $N=9$ ) and pigs (Sus scrofa; $N=1$ ) (Table 1 ). Ticks were observed in body locations as varied as the head, namely in the inner surface of the ears; abdominal area, including scrotum and udder; perineum, tail and limbs.

PCR screening for the presence of tick-borne pathogens revealed an overall prevalence of infection in $R$. bursa of approximately $3.8 \%$ (10/266). Seven ticks (2.6\%) were positive for $16 S \mathrm{rDNA}$ of Anaplasma/Ehrlichia spp. and three were positive for $18 S$ rDNA subunit of Babesia/Theileria spp. (1.1\%). Amplicon sequencing confirmed the presence of $A$. marginale, T. annulata and Theileria equi in $R$. bursa ticks. A. marginale infected ticks were obtained from cattle $(N=3,1$ male and 2 females), sheep ( $N=1$, female), goat $(N=1$, female), and vegetation ( $N=2$, females), in the four subregions IMC Alentejo Litoral, Beira Interior Sul, Alto Alentejo and Peninsula de Setúbal, respectively. T. annulata was found in one male feeding in cattle from IMC Alentejo Litoral; whereas T. equi in two males feeding in horses from IMC Ave. No C. burnetii DNA was detected nor the presence of co-infections.

Phylogenetic analysis using $16 S$ rDNA from different worldwide isolates of $A$. marginale and other pathogens closely related as A. platys, A. phagocytophilum, E. canis, Ehrlichia ruminantium, E. ewingii and $E$. chaffeensis confirmed infection with $A$. marginale (Fig. 2). Blast analysis showed that the four sequences obtained both from questing and cattle parasitizing ticks (with the accession no. A. marginale Portugal KT004409, KT004411 and KT004412 in Fig. 2) presented between 98 and $100 \%$ identify to the bovine strain KNP/M8/a (labeled as A. marginale South Africa accession no. KC189852 in Fig. 2). The remaining sequences from ticks collected from small ruminants and vegetation (with the accession no. A. marginale Portugal KT004414, KT004410 and labeled as A. marginale Portugal.2 in Fig. 2) presented between 97 and 99\% identify to the clone Luzon (labeled as A. marginale Philippines accession no. LC007100 in Fig. 2). The two sequences from T. equi detected in an infected horse (with the accession no. T. equi Portugal KT004407 and KT004408 in Fig. 3) clustered together with T. equi isolates from Brazil and South Africa. Finally, an isolated labeled as Theileria sp. Portugal KT004406 (Fig. 3) did not show clear phylogenetic relationship with any of the Theileria spp. used in the phylogenetic analysis. However, this isolate showed $96 \%$ similarity to a sequence detected in Hyalomma anatolicum from Tajikistan (labeled as $T$. annulata Tajikistan accession no. KM288519 in Fig. 3).

\section{Discussion}

$R$. bursa is widely distributed across the Mediterranean region, including Portugal. In Portugal the presence of this tick species was first recognized in 1943 by Aboim-Inglês (Tendeiro, 1963), and subsequently reported in several areas and on different vertebrate hosts (de Sousa et al., 2011; Santos-Silva et al., 2011, 2012, 2014). In the present study, $R$. bursa were collected from six species of domestic animals (B. taurus, E. caballus, C. hircus, O. aries, C. familiaris and 


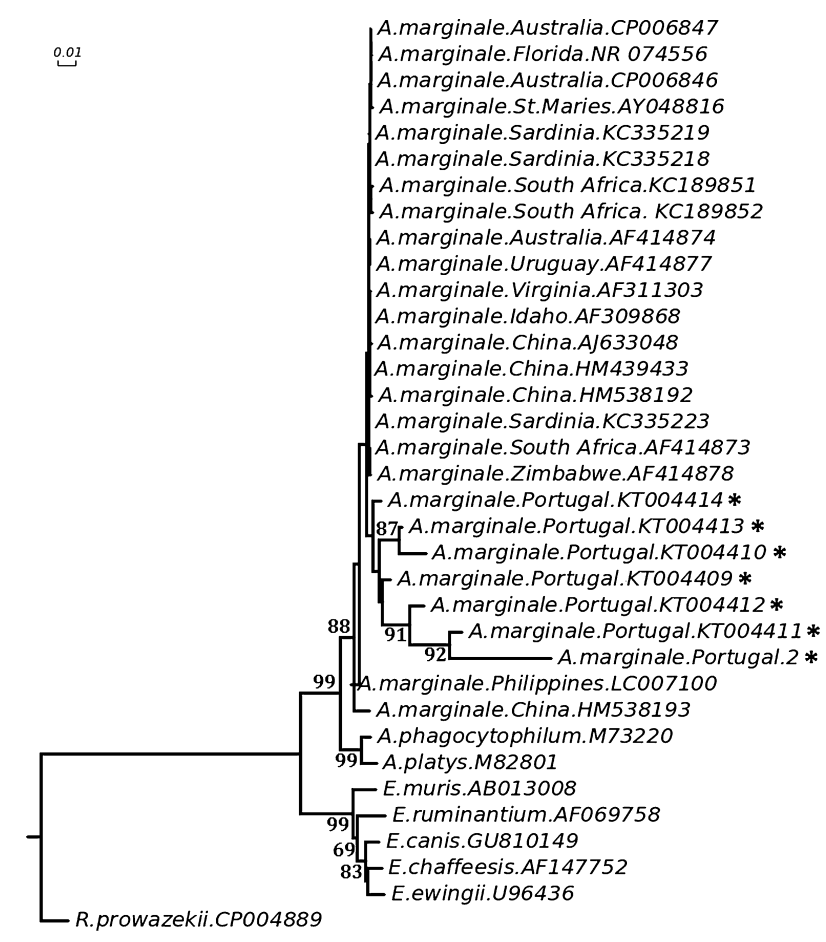

Fig. 2. Phylogenetic tree of Anaplasmataceae using 16S ribosomal RNA gene sequences. The evolutionary history was inferred by using the NJ method based on the Kimura 2-parameter model. $16 S$ rDNA gene nucleotide sequences from $A$. marginale, A. phagocytophilum, A. platys, E. canis, E. chaffeensis, E. ewingii, E. canis (family Anaplasmataceae) were used. Accession numbers of sequences are shown and isolates from Portugal reported in this study are marked with "*”. Numerals on branches are bootstrap values (1000 replicates). $R$. prowazekii was used as outgroup to Anaplasmataceae. An accession no. was not attributed to the isolate A. marginale. Portugal. 2 due to the short size of the sequence.

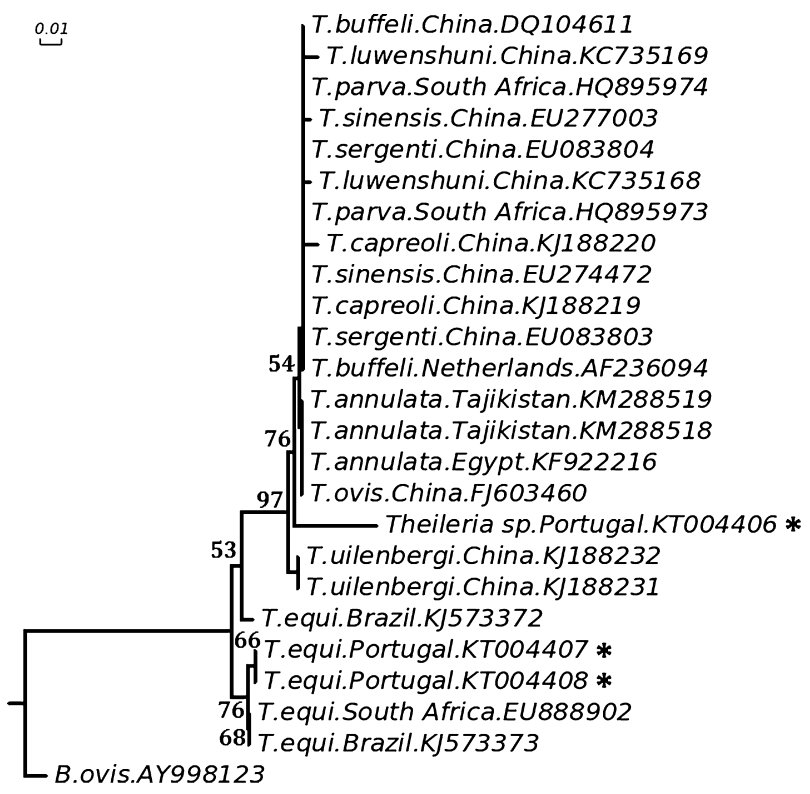

Fig. 3. Phylogenetic tree of Theileria using $18 S$ ribosomal RNA gene sequences. The evolutionary history was inferred by using the $\mathrm{NJ}$ method based on the Kimura 2-parameter model. $18 S$ rDNA gene nucleotide sequences from T. buffeli, T. equi, $T$. annulata, T. parva, T. ovis, T. capreoli, T. luwenshuni, T. sinensis, T. sergenti, T. uilenbergi (Order Piroplasmida) were used. Accession numbers of sequences are shown and isolates from Portugal reported in this study are marked with "**. Numerals on branches are bootstrap values (1000 replicates). Babesia ovis was used as outgroup to Theileria.
S. scrofa), all previously included in the list of hosts parasitized by this tick species. Moreover, this report also confirms the occurrence of $R$. bursa in 22 out of the 68 prior recorded municipalities, from a total of 278 Mainland LAU (de Sousa et al., 2011; Santos-Silva et al., 2011, 2012, 2014). New data on geographical distribution includes the identification of this species in two additional municipalities from the subregion of Alto Alentejo. Interestingly, this is also the first report of $R$. bursa larvae detection in Portugal. The three larvae were collected from cattle from Alto Alentejo; and together with a group of 45 nymphs, reinforces the association of the immature instars to ungulates, as discussed in previous studies (Santos-Silva et al., 2011). The presented data shows that $R$. bursa is active during all year, with a marked seasonal behavior according to the developmental stage, with adults being present mostly during the spring-summer months (May to September) and immature in autumn-winter (October to January-February). This is in agreement with the findings of other studies, although the majority of the available data refers to adult ticks (de Sousa et al., 2011; SantosSilva et al., 2011, 2012, 2014). Although the highest numbers of ticks were collected in the summer (75.2\%), this might reflect not only species seasonal tendency but also the tick active surveillance during cattle vaccination campaigns and other livestock management. Few surveys conducted in Portugal have found nymphs of $R$. bursa, and all specimens were obtained on cattle, goats, sheep and mice (Santos-Silva et al., 2011). Nevertheless, the reduced number of reports regarding immatures is likely to be due to a limited screening of ungulates during colder months. During our study we have found an equivalent ratio of male: female. Although a similar ratio of male: female has been reported (Garcia-Sanmartin et al., 2008), most studies report that the number of males generally outnumbers the number of females (Moshaverinia et al., 2012; Papadopoulos et al., 1996; Yeruham et al., 1996). As mentioned, the primary hosts of this tick species include cattle, sheep, and goats; and less frequently dogs and smaller mammals, such as rabbits (de la Fuente et al., 2004a; Masala et al., 2012; Mihalca et al., 2012; Psaroulaki et al., 2006; Santos-Silva et al., 2011; Satta et al., 2011; Walker et al., 2000). Here, $R$. bursa ticks were removed mainly from large mammals such as cattle and horses; and in lesser numbers from goats, sheep, and dogs. This result may be linked to the fact that the present survey was not designed to compare $R$. bursa host preference, but to primarily contribute to a broader insight on the tick $R$. bursa distribution. Nevertheless, our results are very similar to the ones described in a study conducted in Sardinia (Satta et al., 2011). Additionally, $R$. bursa is described to have preference for particular areas of the host body, according to tick instars and the host species (Estrada-Pena et al., 2004; Yeruham et al., 1989). Indeed, in this study distinct locations were recorded although the reduced number of collected ticks limits any statistical inference. In cattle, the highest number of adult ticks was collected from the abdominal and perineal areas, contrasting with the immatures that were mainly found on the head and dorsal regions. The same observations were recorded by other authors (Estrada-Pena et al., 2004; Feldman-Muhsam, 1953; Papadopoulos et al., 1996). More specifically, in horses and goats most of the adult $R$. bursa were collected from the posterior regions of the body, including perineum and tail and perineum and udder, respectively; in sheep and dogs, ticks were found mostly on the head, mainly from the inner surface of the ears, similarly to what have been reported elsewhere (FeldmanMuhsam, 1953; Papadopoulos et al., 1996). No specimens were found on other locations already described for these hosts, such as the tail, perianal and inguinal areas, interdigital spaces and axilla, for sheep (Moshaverinia et al., 2012; Papadopoulos et al., 1996; Yeruham et al., 1989); and neck, breast and the interdigital spaces, for dogs (Papadopoulos et al., 1996).

Molecular results confirmed the presence of $A$. marginale, $T$. annulata and $T$. equi in $R$. bursa ticks. A. marginale was found in 
ticks feeding in cattle, sheep, and goats, and among questing ticks. T. annulata was found in a tick feeding in cattle; and T. equi in ticks feeding in horses. Despite the detection of these three pathogens, it was not possible to conclude about the vector capacity of this tick species. To address this one would need more evidence, firstly because the biologic material was obtained from the complete tick and the pathogen could be present only in the midgut and not in the salivary glands from where it would be transmitted via saliva; secondly, a positive PCR does not confirm that these pathogens are capable of multiplication in this tick and thus transmitted. Additionally, once the blood of each animal was not tested the origin of each pathogen was not determined. Two possible sources of tick infection could be implicated: the blood meal on the host from where the tick was collected, or the blood meal from the previous host through transstadial transmission.

In Portugal and Spain, $R$. bursa is a proven vector of $A$. marginale and the infection of cattle, known as bovine anaplasmosis, caused by this pathogen has been already reported (Caeiro, 1999; de la Fuente et al., 2004a; Kocan et al., 2004). Bovine anaplasmosis is now known to be endemic in tropical and subtropical regions worldwide, causing substantial economic losses to cattle industries (Kocan et al., 2003). T. annulata is mainly transmitted by ticks of the genus Hyalomma; however, similarly to our study, R. bursa was also associated with the transmission of this pathogen in Tunisia (M'Ghirbi et al., 2010). In cattle, T. annulata is the causative agent of tropical theileriosis responsible for serious constraints on the animal health and productivity worldwide due to high morbidity and mortality (Branco et al., 2010; Doliveira et al., 1995). In Portugal, the presence of this tick-borne pathogen has already been reported in cattle during an acute lethal infection of calves highly infested by ticks of the genus Hyalomma (Branco et al., 2010), and during a survey conducted in asymptomatic cattle for detection of piroplasms (Gomes et al., 2013). Nevertheless, we were not able to identify any study conducted in Portugal that has isolated T. annulata from $R$. bursa ticks. T. equi (formerly known as Babesia equi) can be naturally transmitted by ticks of the family Ixodidae (Stiller et al., 2002) and $R$. bursa has been implicated as the vector of piroplasmosis caused by $T$. equi in horses in Spain and Iran (Abedi et al., 2014; Garcia-Sanmartin et al., 2008). Similarly, we have found $T$. equi in ticks of this species infesting horses. Previous studies conducted in Portugal report the detection of this pathogen in samples collected from horses (Baptista et al., 2013; Ribeiro et al., 2013) but, to date, no reports were found relating $R$. bursa with $T$. equi in our country. Equine piroplasmosis is endemic in the north of Portugal (Ribeiro et al., 2013) and it is estimated that $90 \%$ of the equine population worldwide lives in areas where equine piroplasmosis is present (Dewaal, 1992). Nowadays, equine piroplasmosis has serious implications for increasing international trade of horses (Ros-Garcia et al., 2013). To the best of our knowledge, our report is the first to identify T. annulata and T. equi in $R$. bursa ticks feeding in domestic cattle and horses, respectively, in Portugal.

\section{Conclusions}

Ticks and tick-borne diseases are a current and emerging global threat for human and animal species. The impact of global climate change, human activities, including land management, habitat destruction and control strategies that rely on the use of pesticides, might be responsible for a change in tick biology and possibly contribute to the rapid annual rise in the tick population (Heyman et al., 2010; Omeragic, 2011; Santos-Silva et al., 2011). The results of this study indicate that in Portugal, $R$. bursa can be found on hosts such as cattle, smaller ruminants, such as sheep and goats, horses, and occasionally dogs. Also, this tick is active during all year, with a marked seasonal behavior according to the developmental stage. Our study also demonstrates that several pathogens responsible for tick-borne diseases, particularly A. marginale, T. annulata and $T$. equi, do exist in $R$. bursa ticks and circulate in determined areas of Portugal. Moreover, all positive ticks only harbored a single infection. Here we report for the first time the detection of $T$. annulata and $T$. equi amongst $R$. bursa ticks feeding in domestic cattle and horses, respectively, in Portugal. The confirmation of the presence of Anaplasma and Theileria in Portugal is of extreme importance as both pathogens exert great impact in animal health, influencing animal production and trading. Finally, information about the prevalence of infection in ticks is essential to provide information in order to develop future effective preventive and control strategies.

\section{Conflict of interest}

The authors declare no competing personal or financial interests.

\section{Acknowledgments}

The authors would like to acknowledge Varda Shkap (Kimron Veterinary Institute, Israel) for kindly providing $B$. bigemina and T. annulata controls and also José de la Fuente (SaBio, Instituto de Investigación en Recursos Cinegéticos, Spain) for the A. marginale control. A special acknowledge to Daniel Bacellar for his collaboration in tick collection. We also would like to recognize Nuno Domingues (Faculdade de Ciências da Universidade de Lisboa) for the contribution on tick DNA extraction and Ana Buxo (Instituto Superior Técnico de Lisboa) for the help with QGIS software. This research was supported by the projects PTDC/CVT-EPI/4339/2012 and PTDC/SAU-SAP/115266/2009, funded by the Fundação para a Ciência e Tecnologia.

\section{References}

Abedi, V., Razmi, G., Seifi, H., Naghibi, A., 2014. Molecular and serological detection of Theileria equi and Babesia caballi infection in horses and ixodid ticks in Iran. Ticks Tick-Borne Dis. 5, 239-244.

Altay, K., Aktas, M., Dumanli, N., 2008. Detection of Babesia ovis by PCR in Rhipicephalus bursa collected from naturally infested sheep and goats. Res. Vet. Sci. 85, 116-119.

Antunes, S., Merino, O., Lerias, J., Domingues, N., Mosqueda, J., de la Fuente, J., Domingos, A., 2015. Artificial feeding of Rhipicephalus microplus female ticks with anti calreticulin serum do not influence tick and Babesia bigemina acquisition. Ticks Tick-Borne Dis. 6, 47-55

Baptista, C., Lopes, M.S., Tavares, A.C., Rojer, H., Kappmeyer, L., Mendonca, D., Machado, A.D.C., 2013. Diagnosis of Theileria equi infections in horses in the Azores using cELISA and nested PCR. Ticks Tick-Borne Dis. 4, 242-245.

Beati, L., Keirans, J.E., 2001. Analysis of the systematic relationships among ticks of the genera Rhipicephalus and Boophilus (Acari:Ixodidae) based on mitochondrial $12 S$ ribosomal DNA gene sequences and morphological characters. J. Parasitol. $87,32-48$

Bell-Sakyi, L., Zweygarth, E., Blouin, E.F., Gould, E.A., Jongejan, F., 2007. Tick cell lines: tools for tick and tick-borne disease research. Trends Parasitol. 23, 450-457.

Boudebouch, N., Sarih, M., Socolovschi, C., Amarouch, H., Hassar, M., Raoult, D., Parola, P., 2009. Molecular survey for spotted fever group rickettsiae in ticks from Morocco. Clin. Microbiol. Infect. 15, 259-260.

Branco, S., Orvalho, J., Leitao, A., Pereira, I., Malta, M., Mariano, I., Carvalho, T., Baptista, R., Shiels, B.R., Peleteiro, M.C., 2010. Fatal cases of Theileria annulata infection in calves in Portugal associated with neoplastic-like lymphoid cell proliferation. J. Vet. Sci. 11, 27-34

Caeiro, V., 1999. General review of tick species present in Portugal. Parassitologia 41 (Suppl 1), 11-15.

Castresana, J., 2000. Selection of conserved blocks from multiple alignments for their use in phylogenetic analysis. Mol. Biol. Evol. 17, 540-552.

Colebrook, E., Wall, R., 2004. Ectoparasites of livestock in Europe and the Mediterranean region. Vet. Parasitol. 120, 251-274.

Dantas-Torres, F., Chomel, B.B., Otranto, D., 2012. Ticks and tick-borne diseases: a One Health perspective. Trends Parasitol. 28, 437-446.

de la Fuente, J., Naranjo, V., Ruiz-Fons, F., Vicente, J., Estrada-Pena, A., Almazan, C., Kocan, K.M., Martin, M.P., Gortazar, C., 2004a. Prevalence of tick-borne pathogens in ixodid ticks (Acari:Ixodidae) collected from European wild boar (Sus scrofa) and Iberian red deer (Cervus elaphus hispanicus) in central Spain. Eur. J. Wildl. Res. 50, 187-196. 
de la Fuente, J., Vicente, J., Hofle, U., Ruiz-Fons, F., de Mera, I.G.F., Van Den Bussche, R.A., Kocan, K.M., Gortazar, C., 2004b. Anaplasma infection in free-ranging Iberian red deer in the region of Castilla-La Mancha, Spain. Vet. Microbiol. 100, 163-173.

de Sousa, R., Barata, C., Vitorino, L., Santos-Silva, M., Carrapato, C., Torgal, J., Walker, D., Bacellar, F., 2006. Rickettsia sibirica isolation from a patient and detection in ticks, Portugal. Emerg. Infect. Dis. 12, 1103-1108.

de Sousa, R., Lopes de Carvalho, I., Santos, A., Santos-Silva, M., Alves, M., Núncio, S., 2011. Ixodídeos, Relatório REVIVE 2011 - Culicídeos e Ixodídeos (excerto): Rede de Vigilância de Vectores. In: Repositório Científico do Instituto Nacional de Saúde Doutor Ricardo Jorge.

Dewaal, D.T., 1992. Equine piroplasmosis - a review. Br. Vet. J. 148, 6-14.

Doliveira, C., Vanderweide, M., Habela, M.A., Jacquiet, P., Jongejan, F., 1995. Detection of Theileria annulata in blood-samples of carrier cattle by PCR. J. Clin. Microbiol. 33, 2665-2669.

Estrada-Pena, A., Bouattour, A., Camicas, J.-L., Walker, A., 2004. Ticks of domestic animals in the Mediterranean Region International Consortium on Ticks and Tick-Borne Diseases Atlanta, The Netherlands.

Feldman-Muhsam, B., 1953. Rhipicephalus bursa in Israel. Bull. Res. Counc. Isr. 201-206.

Garcia-Sanmartin, J., Barandika, J.F., Juste, R.A., Garcia-Perez, A.L., Hurtado, A. 2008. Distribution and molecular detection of Theileria and Babesia in questing ticks from northern Spain. Med. Vet. Entomol. 22, 318-325.

Gomes, J., Soares, R., Santos, M., Santos-Gomes, G., Botelho, A., Amaro, A., Inacio, J. 2013. Detection of Theileria and Babesia infections amongst asymptomatic cattle in Portugal. Ticks Tick-Borne Dis. 4, 148-151.

Harrus, S., Perlman-Avrahami, A., Mumcuoglu, K.Y., Morick, D., Eyal, O., Baneth, G., 2011. Molecular detection of Ehrlichia canis, Anaplasma bovis, Anaplasma platys, Candidatus Midichloria mitochondrii and Babesia canis vogeli in ticks from Israel. Clin. Microbiol. Infect. 17, 459-463.

Heyman, P., Cochez, C., Hofhuis, A., van der Giessen, J., Sprong, H., Porter, S.R., Losson, B., Saegerman, C., Donoso-Mantke, O., Niedrig, M., Papa, A., 2010. A clear and present danger: tick-borne diseases in Europe. Expert Rev. Anti-Infect. Ther. 8, 33-50.

Inokuma, H., Raoult, D., Brouqui, P., 2000. Detection of Ehrlichia platys DNA in brown dog ticks (Rhipicephalus sanguineus) in Okinawa Island, Japan. J. Clin. Microbiol. 38, 4219-4221.

Ioannou, I., Sandalakis, V., Kassinis, N., Chochlakis, D., Papadopoulos, B., Loukaides, F., Tselentis, Y., Psaroulaki, A., 2011. Tick-borne bacteria in mouflons and their ectoparasites in Cyprus. J. Wildl. Dis. 47, 300-306.

Jongejan, F., Uilenberg, G., 2004. The global importance of ticks. Parasitology 129 S3-S14.

Katoh, K., Standley, D.M., 2013. MAFFT multiple sequence alignment software version 7: improvements in performance and usability. Mol. Biol. Evol. 30 $772-780$.

Kocan, K.M., De La Fuente, J., Blouin, E.F., Garcia-Garcia, J.C., 2004. Anaplasma marginale (Rickettsiales:Anaplasmataceae): recent advances in defining host-pathogen adaptations of a tick-borne rickettsia. Parasitology 129, S285-S300.

Kocan, K.M., de la Fuente, J., Guglielmone, A.A., Melendez, R.D., 2003. Antigens and alternatives for control of Anaplasma marginale infection in cattle. Clin. Microbiol. Rev. 16, 698.

Labuda, M., Nuttall, P.A., 2004. Tick-borne viruses, Parasitology 129, S221-S245.

Lorenz, H., Jager, C., Willems, H., Baljer, G., 1998. PCR detection of Coxiella burnetii from different clinical specimens, especially bovine milk, on the basis of DNA preparation with a silica matrix. Appl. Environ. Microbiol. 64, 4234-4237.

M'Ghirbi, Y., Hurtado, A., Bouattour, A., 2010. Theileria and Babesia parasites in ticks in Tunisia. Transbound. Emerg. Dis. 57, 49-51.

Masala, G., Chisu, V., Foxi, C., Socolovschi, C., Raoult, D., Parola, P., 2012. First detection of Ehrlichia canis in Rhipicephalus bursa ticks in Sardinia, Italy. Ticks Tick-Borne Dis. 3, 395-396.

Mihalca, A.D., Dumitrache, M.O., Magdas, C., Gherman, C.M., Domsa, C., Mircean, V., Ghira, I.V., Pocora, V., Ionescu, D.T., Barabasi, S.S., Cozma, V., Sandor, A.D., 2012.
Synopsis of the hard ticks (Acari:Ixodidae) of Romania with update on host associations and geographical distribution. Exp. Appl. Acarol. 58, 183-206.

Moshaverinia, A., Dini, M., Azizzadeh, M., 2012. Prevalence of ixodid tick infestation of sheep in the Arasbaran region of Iran. J. Parasit. Dis. 36 230-233.

Omeragic, J., 2011. Ixodid ticks in Bosnia and Herzegovina. Exp. Appl. Acarol. 53, 301-309.

Papadopoulos, B., Brossard, M., Perie, N.M., 1996. Piroplasms of domestic animal in the Macedonia region of Greece. 2. Piroplasms of cattle. Vet. Parasitol. 63, 57-66.

Psaroulaki, A., Ragiadakou, D., Kouris, G., Papadopoulos, B., Chaniotis, B., Tselentis, Y., 2006. Ticks, tick-borne Rickettsiae, and Coxiella burnetii in the Greek Island of Cephalonia. Century of Rickettsiology: Emerging, Reemerging Rickettsioses, Molecular Diagnostics, and Emerging Veterinary Rickettsioses, vol. 1078. pp. 389-399.

Ribeiro, A.J., Cardoso, L., Maia, J.M., Coutinho, T., Cotovio, M., 2013. Prevalence of Theileria equi, Babesia caballi, and Anaplasma phagocytophilum in horses from the north of Portugal. Parasitol. Res. 112, 2611-2617.

Ros-Garcia, A., M'Ghirbi, Y., Hurtado, A., Bouattour, A., 2013. Prevalence and genetic diversity of piroplasm species in horses and ticks from Tunisia. Infect. Genet. Evol. 17, 33-37.

Santos-Silva, M., Santos, A., Lopes de Carvalho, I., de Sousa, R., Alves, M., Núncio, S., 2012. Ixodideos, Ixodídeos In Relatório REVIVE 2012 - Culicídeos e Ixodídeos (excerto): Rede de Vigilância de Vectores. In: Repositório Científico do Instituto Nacional de Saúde Doutor Ricardo Jorge.

Santos-Silva, M., Santos, A., Lopes de Carvalho, I., De Sousa, R., Milhano, N., Osório, H., Alves, M., Núncio, S., 2014. Ixodídeos, Relatório REVIVE 2013 - Culicídeos e Ixodídeos (excerto): Rede de Vigilância de Vectores. In: Repositório Científico do Instituto Nacional de Saúde Doutor Ricardo Jorge.

Santos-Silva, M.M., Beati, L., Santos, A.S., De Sousa, R., Nuncio, M.S., Melo, P., Santos-Reis, M., Fonseca, C., Formosinho, P., Vilela, C., Bacellar, F., 2011. The hard-tick fauna of mainland Portugal (Acari:Ixodidae): an update on geographical distribution and known associations with hosts and pathogens. Exp. Appl. Acarol. 55, 85-121.

Satta, G., Chisu, V., Cabras, P., Fois, F., Masala, G., 2011. Pathogens and symbionts in ticks: a survey on tick species distribution and presence of tick-transmitted micro-organisms in Sardinia, Italy. J. Med. Microbiol. 60, 63-68.

Stiller, D., Goff, W.L., Johnson, L.W., Knowles, D.P., 2002. Dermacentor variabilis and Boophilus microplus (Acari:Ixodidae): experimental vectors of Babesia equi to equids. J. Med. Entomol. 39, 667-670.

Tamura, K., Stecher, G., Peterson, D., Filipski, A., Kumar, S., 2013. MEGA6: molecula evolutionary genetics analysis version 6.0. Mol. Biol. Evol. 30, 2725-2729.

Tendeiro, J., 1963. Revisão sistemática dos ixodídeos portugueses. Sep. Bol Pecuário, ano XXX, Lisboa, Portugal.

Toledo, A., Sonia Olmeda, A., Escudero, R., Jado, I., Valcarcel, F., Casado-Nistal, M.A Rodriguez-Vargas, M., Gil, H., Anda, P., 2009. Tick-borne zoonotic bacteria in ticks collected from central Spain. Am. J. Trop. Med. Hyg. 81, 67-74.

Walker, J.B., Keirans, J.E., Horak, I.G., 2000. The Genus Rhipicephalus (Acari, Ixodidae): A Guide to the Brown Ticks of the World.

Yeruham, I., Hadani, A., Galker, F., Mauer, E., Rubina, M., Rosen, S., 1985. The geographical distribution and animal hosts of Rhipicephalus bursa (Canestrini and Fanzago, 1877) in Israel. Revue d'elevage et de Medecine Veterinaire des Pays Tropicaux 38, 173-179.

Yeruham, I., Hadani, A., Galker, F., Rosen, S., 1989. Notes on the biology of the tick Rhipicephalus bursa (Canestrini and Fanzago, 1877) in Israel. Revue d'elevage et de Medecine Veterinaire des Pays Tropicaux 42, 233-235.

Yeruham, I., Hadani, A., Galker, F., Rosen, S., 1996. The seasonal occurrence of ticks (Acari:Ixodidae) on sheep and in the field in the Judean area of Israel. Exp. Appl. Acarol. 20, 47-56.

Zhang, H., Gao, S., Lercher, M.J., Hu, S., Chen, W.H., 2012. EvolView, an online tool for visualizing, annotating and managing phylogenetic trees. Nucleic Acids Res. 40. W569-572. 